\title{
Allelic Loss and Tumor Pathology in Head and Neck Squamous Cell Carcinoma
}

Benjamin A. Rybicki, Ph.D., Adnan T. Savera, M.D., Jose A. Gomez, M.D., Sonal C. Patel, B.S., Nicole E. Ballard, B.S., Michael S. Benninger, M.D., Richard J. Zarbo, M.D., Daniel L. Van Dyke, Ph.D.

Departments of Biostatistics and Research Epidemiology (BAR), Surgical Pathology (ATS, JAG, RJZ), Medical Genetics (SCP, NEB, DLVD), and Otolaryngology (MSB), Henry Ford Health System, Detroit, Michigan

Allelic loss is a common occurrence in head and neck tumors and has been shown to be an independent predictor of prognosis; however, the relationship between allelic loss and tumor pathology is not well-known. We studied 139 patients who were newly diagnosed with squamous cell cancer of the head and neck to determine whether tumor pathology was correlated with allelic loss at one or more of eight different regions on chromosomes $3 p, 5 q, 8 p$, 9p, 10p, 18q, and 21q. At each chromosomal region, loss of heterozygosity at any one of three or four highly polymorphic microsatellite markers that spanned the region in question was considered evidence for allelic loss. A pathologist scored all tumors for seven tumor pathology and host interface parameters. Mean allelic loss across all eight regions was associated with mitotic index $(P=.034)$ and inflammatory response $(P=.005)$. For allelic loss at specific chromosomal regions, the most statistically significant trends were between overall tumor grade and 3p14.2-p13 $(P=.014)$, mitotic index and 3p24.3-p14.3 $(P=.026), 9$ 24.2-p21 $(P=.004)$ and 18q12.3-q23 $(P=.009)$, inflammatory response and 3p14.2-p13 $(P=.008)$ and 9p24.2-p21 $(P=.001)$, desmoplastic response and 9p24.2-p21 $(P=.009)$, and pattern of invasion and 21q21-q22.2 $(P=.015)$. Our results suggest that genes involved in tumor suppression and oncogenesis can potentially be classified based on specific pathologic events in head and neck squamous cell carcinogenesis that they modify.

\footnotetext{
Copyright () 2003 by The United States and Canadian Academy of Pathology, Inc.

VOL. 16, NO. 10, P. 970, 2003 Printed in the U.S.A.

Date of acceptance: June 16, 2003.

This work was supported by National Institutes of Health grant R01CA070093.

Address reprint requests to: Benjamin A. Rybicki, Ph.D., Department of Biostatistics and Research Epidemiology, Henry Ford Health System, 1 Ford Place, 3E, Detroit, MI 48202; fax: 313-874-6730; e-mail: brybick1@hfhs.org.

DOI: 10.1097/01.MP.0000086627.74271.13
}

KEY WORDS: Chromosomal deletion Loss of heterozygosity, Oncogene, Tumor suppressor gene.

Mod Pathol 2003;16(10):970-979

Allelic loss in chromosomal regions surrounding known or suspected tumor suppressor genes has been shown to be an important marker of head and neck squamous cell carcinoma prognosis (1-7). Regions of loss reported to lead to a poorer prognosis include 3p21(6), 5q21 (4), 8p21-23 (2, 8), 9p21 (9), $10 q$ (1), 11p (3), 14q (7), and 18q (5). Results vary across studies with regard to the importance of allelic loss in these regions and head and neck squamous cell carcinoma survival or recurrence. In individuals with precancerous oral lesions, allelic loss at $3 p$ and $9 p(10-13)$ appears important in predicting who will advance to invasive oral cancer. A recent study showed allelic loss at 5q21-q23 to be most strongly associated with foci of early cancerization in leukoplakia tissue samples (14). Overall, studies of allelic loss in premalignant and malignant head and neck lesions suggest that chromosomal losses occur in characteristic patterns that likely guide the prospective tumor cell population along the multistep carcinogenesis pathway.

Studies of histologic markers as predictors of disease outcome in head and neck squamous cell carcinoma have also been conducted. These studies have focused on tumor and host interface parameters such as tumor grade, mitotic index, tumor desmoplasia, and inflammatory response. Klijanienko et al. (15) found a strong association between the tumor mitotic index and tumor vascularization in 114 head and neck neoplasms. Yilmaz et al. (16) found that mode of tumor invasion to surrounding tissues was associated with laryngeal cancer survival. Janot et al. (17) found no histologic parameters associated with overall survival in 108 head and neck cancer patients. Another similar study of 37 oral cancer patients found no association between tumor desmoplasia and survival (18). These head and neck cancer histologic parameters do not ap- 
pear to have any clear prognostic significance, but their relationship to the overall carcinogenic pathway in head and neck squamous cell carcinoma may be more appreciated with a better understanding of how these pathologic events are mediated at the cellular DNA level.

Relating allelic loss in tumors to tumor and host interface parameters has some clear advantages over studying the relationship of each with respect to crude clinical events. Drawing associations between the tumor cell's pathology and allelic loss may lead to identification of the gene or gene(s) that mediate tumor growth and development, tumor spread, and the host reaction to tumor cells. This information could be useful in preventive treatments targeted at genes involved in early pathologic events or curative treatments aimed at genes involved in host response.

In the present study, we tested for associations between different tumor and host interface parameters and allelic loss in specific chromosomal regions. Our objective was to determine whether chromosomal loss could be used to characterize the pathologic state of the primary head and neck tumor. If so, then one or more tumor suppressor genes or oncogenes localized to these areas of loss might be implicated for their role in inducing and/or maintaining specific pathologic phenomena.

\section{METHODS}

\section{Study Population}

Head and neck squamous cell carcinoma cases were identified during the Henry Ford Hospital Head and Neck Tumor Conference in the department of otolaryngology. Eligible cases had newly diagnosed primary head and neck tumors that were histologically confirmed as squamous cell in origin. Primary nasopharyngeal tumors were excluded. In total, 184 eligible cases that consented for study were enrolled between January 1996 and April 2000. Of these, $141(76.6 \%)$ cases had sufficient tissue samples for DNA and pathologic analysis.

\section{DNA Extraction from Tumor Tissue}

Tumor tissue of cases was obtained either at time of surgery or through paraffin blocks. Tumor tissue was microdissected from paraffin blocks using a \#15 scalpel and placed into 1.5-mL microcentrifuge tubes for DNA extraction; $200 \mu \mathrm{L}$ of lysis buffer (10 mм Tris- $\mathrm{HCl}, \mathrm{pH}$ 8.3; $50 \mathrm{~mm} \mathrm{KCl} ; 2.5 \mathrm{~mm} \mathrm{MgCl}_{2}$; $0.45 \%$ Tween 20) was added. The tubes were then boiled for 10 minutes and spun at 10,000 rpm for 5 minutes. The paraffin wax layer was then removed. Next, $5 \mu \mathrm{L}$ of proteinase $\mathrm{K}(20 \mathrm{mg} / \mathrm{mL})$ was added and tubes were incubated at $55^{\circ} \mathrm{C}$ with constant shaking for 2 hours. The product was boiled at $100^{\circ} \mathrm{C}$ for 10 minutes and processed by centrifuge for 5 minutes at 10,000 rpm. The DNA supernatant was then transferred into a new tube and stored at $-20^{\circ} \mathrm{C}$.

The tumor tissue fragment processed for DNA extraction was first histologically evaluated for the percentage of tumor purity. Subsequently, DNA was extracted by adding $1 \mathrm{~mL}$ of nuclei lysis buffer (75 mm NaCl, $24 \mathrm{~mm}$ EDTA) to the ground surgical specimen. This mixture was transferred to a conical tube; $22 \mu \mathrm{L}$ of proteinase $\mathrm{K}(20 \mathrm{mg} / \mathrm{mL})$ and $200 \mu \mathrm{L}$ of sodium dodecyl sulfate were added. The contents were incubated at $37^{\circ} \mathrm{C}$ overnight on a shaker. The following day, an equal volume of phenolchloroform mixture was added; the supernatant was removed, and the phenol-chloroform mixture step was repeated on the remaining contents of the tube. Next, $3 \mathrm{~m}$ sodium acetate and isopropanol were added to the supernatant in a 1:1:10 ratio and stored overnight at $-20^{\circ} \mathrm{C}$. The isopropanol was removed, and the pellet was rinsed with $70 \%$ ethanol. One hundred microliters of Tris EDTA was added to dissolve the pellet; this product was then stored at $4^{\circ} \mathrm{C}$. Normal DNA was extracted from blood specimens per protocol using a nonorganic DNA extraction kit from Oncor (Gaithersburg, MD).

\section{DNA Analysis}

The DNA products from both tumor and blood specimens were amplified using standard PCR methods. Normal and tumor amplified DNA products were run on a $6 \%$ acrylamide gel on the Bio-Rad Sequi-Gen Sequencing System (Hercules, CA) in parallel (normal and tumor DNA of each patient) at 2000 volts at $45-50^{\circ} \mathrm{C}$ for 2 to 4 hours. The gel was then bonded to filter paper, dried, and placed into an autoradiography cassette with a piece of film. The exposed film was developed the following day for analysis. Allelic loss was assessed as loss of heterozygosity in tumor cell diploid DNA at eight different chromosomal regions (3p14.2-p13, 3p24.3-p14.3, 5q11.2-q31.3, 8p21.3-11.2, 9p24.2p21, 10p12.1-p11.2, 18q12.3-q23, and 21q21q22.2) that were chosen based on the proximity of known tumor suppressor genes or oncogenes. Table 1 describes the names and relative locations of the markers used in this study. Loss of heterozygosity was measured by the genotypes of three or four microsatellite repeat markers located within the regions. We considered a region to have loss of heterozygosity if at least one of the markers tested within the region of interest had a missing allele in the DNA from the tumor sample (based on a $50 \%$ reduction in signal intensity). 
TABLE 1. Description of Chromosomal Regions Studied

\begin{tabular}{|c|c|c|}
\hline Cytogenetic Bands & $\begin{array}{l}\text { Genetic } \\
\text { Markers }\end{array}$ & $\begin{array}{l}\text { Location in Megabases } \\
\text { from p Terminal Arm }\end{array}$ \\
\hline \multirow[t]{3}{*}{ 3p24.3-p14.3 } & D3S1340 & 17.4 \\
\hline & D3S192 & 20.6 \\
\hline & D3S1241 & 54.3 \\
\hline \multirow[t]{3}{*}{ 3p14.2-p13 } & D3S1067 & 58.5 \\
\hline & D3S1228 & 64.3 \\
\hline & D3S659 & 71.1 \\
\hline \multirow[t]{4}{*}{$5 q 11.2-q 31.3$} & D5S524 & 58.9 \\
\hline & D5S98 & 106.7 \\
\hline & D5S556 & 113.6 \\
\hline & D5S178 & 141.5 \\
\hline \multirow[t]{3}{*}{ 8p21.3-p11.2 } & LPL & 19.6 \\
\hline & NEFL & 25.2 \\
\hline & ANK1 & 41.5 \\
\hline \multirow[t]{3}{*}{$9 \mathrm{p} 24.2-\mathrm{p} 21$} & D9S199 & 17.4 \\
\hline & IFNA & 23.7 \\
\hline & D9S126 & 33.9 \\
\hline \multirow[t]{3}{*}{ 10p12.1-p11.2 } & D10S89 & 26.3 \\
\hline & GLUDP5 & 31.6 \\
\hline & TCF8 & 31.8 \\
\hline \multirow[t]{4}{*}{ 18q12.3-q23 } & D18S34 & 39.1 \\
\hline & D18S336 & 76.0 \\
\hline & MBP122 & 83.7 \\
\hline & MBP228 & 83.7 \\
\hline \multirow[t]{3}{*}{$21 q 21-q 22.2$} & D21S11 & 19.5 \\
\hline & IFNAR & 35.5 \\
\hline & D21S167 & 40.4 \\
\hline
\end{tabular}

\section{Tumor Pathology Measures}

The surgical specimens were routinely processed, and histomorphologic assessments were made using hematoxylin and eosin-stained tissue sections. All squamous cell carcinomas were staged according to the TNM system and cataloged by anatomic site. We employed Crissman and Zarbo's modified Jakobsson scheme (19) that involves a four-level qualitative score assigned to seven tumor parameters. These include four tumor pathology parameters (overall tumor grade, keratinization, nuclear grade, and frequency of mitoses per high-power field) and three tumor-host interface parameters (inflammatory response, desmoplastic response, and pattern of tumor invasion). For the four tumor parameters, the 1 to 4 integer scoring scale represents an increase in the development of the param- eter with respect to what is observed in normal cells. For the tumor-host interface parameters, an incremental increase represents a declining response of the host to the invading tumor. See Table 2 for definitions underlying the scoring scale.

\section{Statistical Analyses}

Both univariate and multivariate techniques were used to examine the associations between pathological parameters and allelic loss in tumor cells. Associations between an increasing prevalence of allelic loss and severity of pathological parameters were tested with a Cochran-Armitage test for trend (20). For pathological parameters in which statistically significant $(P<.05)$ trends of association were observed for two or more regions of allelic loss, multivariate generalized linear models for categorical data were used. The pathological parameter was considered the dependent variable and was modeled to have a multinomial distribution on the cumulative logit scale. Allelic loss variables were parameterized as 0 (retention of heterozygosity) and 1 (loss of heterozygosity) and were chosen based on their univariate associations with the pathological parameter. Allelic loss variables were introduced into the model one at a time and were retained if the reduction in scaled deviance of the model was significant at the $P<.05$ level. Fractional allelic loss was calculated as the mean percentage of allelic loss among the informative regions (of the eight studied) for each individual and represented a summary measure of allelic loss over all eight regions. The association between fractional allelic loss and pathological parameters was tested using analysis of variance statistics.

\section{RESULTS}

Characteristics of Study Population

Table 3 shows the demographic and tumor characteristics of the study population. Two individuals

TABLE 2. Description of Tumor Pathology and Tumor-Host Interface Scoring System

\begin{tabular}{|c|c|c|c|c|}
\hline \multirow{2}{*}{ Tumor Parameters } & \multicolumn{4}{|c|}{ Parameter Score (Increasing Severity $\rightarrow$ ) } \\
\hline & 1 & 2 & 3 & 4 \\
\hline \multicolumn{5}{|l|}{ Tumor pathology } \\
\hline Overall grade & Well differentiated & $\begin{array}{l}\text { Moderately } \\
\text { differentiated }\end{array}$ & Poorly differentiated & Undifferentiated \\
\hline Keratinization & $\begin{array}{l}\text { Prominent (keratin } \\
\text { pearls) }\end{array}$ & $\begin{array}{l}\text { Moderate rare } \\
\text { extracellular deposits }\end{array}$ & Some cellular keratin & Absent \\
\hline Nuclear grade & $\begin{array}{l}\text { Few pleomorphic; } 75 \% \\
\text { mature }\end{array}$ & 50-75\% mature & $\begin{array}{l}\text { Numerous pleomorphic } \\
\text { cells }(25-50 \%)\end{array}$ & Markedly pleomorphic \\
\hline \multicolumn{5}{|l|}{ Tumor-host interface } \\
\hline Mitotic index ${ }^{a}$ & $0-1$ & $2-3$ & $4-5$ & $>5$ \\
\hline Inflammatory response & Continuous rim & Patchy infiltrate & Small aggregates & Absent \\
\hline Desmoplastic response & Prominent and diffuse & Patchy and irregular & Focal & Absent \\
\hline Pattern of invasion & $\begin{array}{l}\text { Pushing cohesive } \\
\text { borders }\end{array}$ & Large cohesive & Small, irregular & Single cells \\
\hline
\end{tabular}

${ }^{a}$ Number of mitoses per high power field. 
TABLE 3. Description of Study Population $(n=139)$

\begin{tabular}{lc}
\hline \multicolumn{1}{c}{ Characteristic } & Percent \\
\hline Race/sex $^{a}$ & 47 \\
Caucasian males & 14 \\
Caucasian females & 28 \\
African-American males & 11 \\
African-American females & \\
Tumor site & 25 \\
Oral cavity & 25 \\
Oropharynx & 11 \\
Hypopharynx & 25 \\
Glottic & 14 \\
Supraglottic & \\
Tumor Stage: & 21 \\
I & 14 \\
II & 22 \\
III & 43 \\
IV & \\
Primary tumor type & 91 \\
Conventional & 7 \\
Non-keratinizing & 2 \\
Papillary squamous &
\end{tabular}

${ }^{a}$ One individual was a Hispanic male.

whose tumor histology upon further pathologic inspection was found to be primarily basaloid $(n=1)$ or adenomatous $(n=1)$ in origin were removed from the analysis data set, resulting in total of 139 cases. Patients were primarily male (76\%), with a racial distribution of about $60 \%$ Caucasian and $40 \%$ African American. The mean age of patients was $62.3 \pm 11.0$ years, with a range between 27 and 86 years. The most prevalent tumor sites were laryngeal $(39 \%)$, followed by pharyngeal $(36 \%)$ and oral cavity tumors (25\%). More than $60 \%$ of patients had stage III or IV cancer at the time of diagnosis. Of the primary pathologic tumor types, more than $90 \%$ were conventional squamous cell type.

\section{Tumor Site and Stage}

Because the 139 cases in the analysis data set comprised patients with tumors at different anatomic sites, before we conducted the primary study analyses, anatomic site-specific differences in either the dependent (allelic loss) or independent (tumor pathology/host interface) parameters were investigated. Significant anatomic site heterogeneity in allelic loss was observed for 3p24.3-p14.3 $(P=$ .042), 3p14.2-p13 ( $P=.007)$, and 18q12.3-q23 ( $P=$ $.003)$. At the 3p24.3-p14.3 region, loss of heterozygosity was higher in pharyngeal (72\%) and laryngeal (72\%) tumors compared with oral cavity tumors (49\%). A similar relationship was observed for the 3 p14.2-p13 region, with greater loss of heterozygosity in pharyngeal $(68 \%)$ and laryngeal $(64 \%)$ tumors compared with oral cavity tumors (35\%). This trend was continued in the 18q12.3-q23 region, with greater loss of heterozygosity in pharyngeal (49\%) and laryngeal $(51 \%)$ tumors compared with oral cavity tumors $(17 \%)$. Figure 1 shows the relationship between the anatomic site of the tumor and

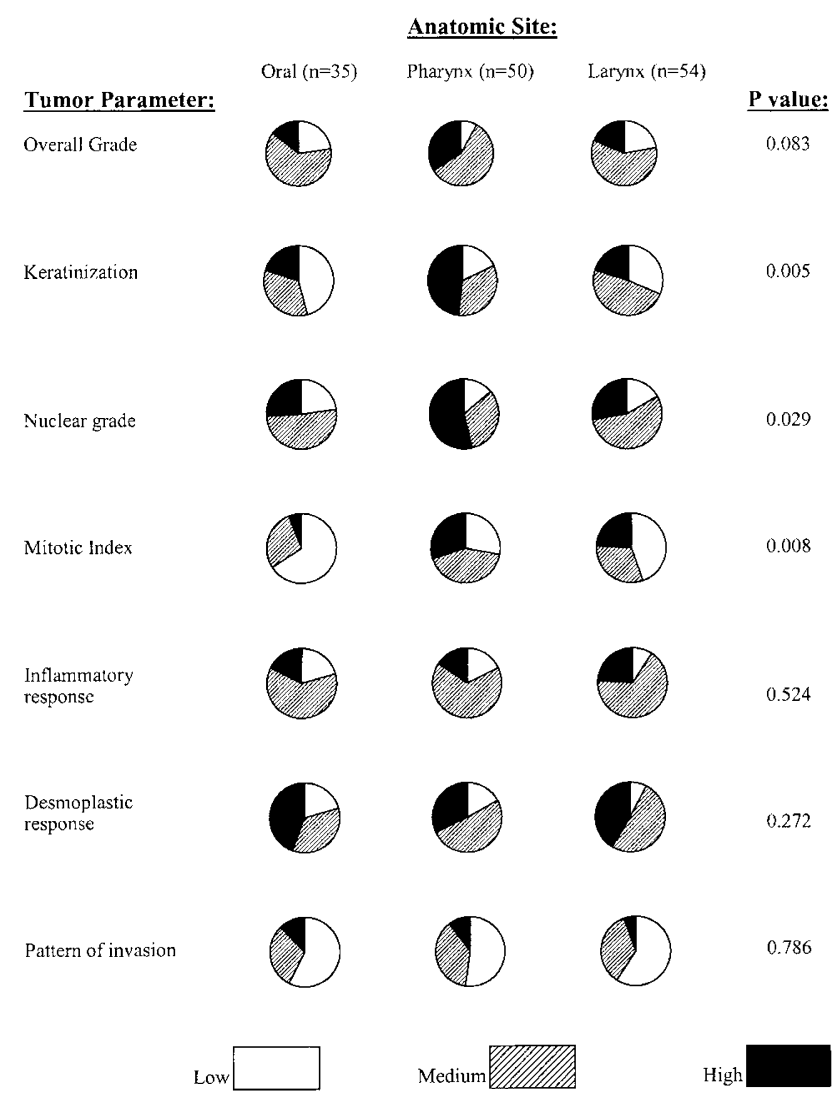

FIGURE 1. Distribution of low (score $=1$ ), medium (score $=2$ ), and high (score $=3$ or 4 ) levels of tumor pathology and host interface parameters with respect to anatomic site of the head and neck tumor.

the seven tumor pathology/host interface parameters. For the purposes of analysis, the four levels in the scoring scheme for the seven tumor parameters were condensed into three levels with the two highest levels collapsed into a single category. Keratinization and mitotic index showed the strongest relationship with anatomic tumor site, with higher tumor scores observed in the laryngeal and pharyngeal tumors compared with the oral cavity tumors. Nuclear grade also showed heterogeneity, albeit less significant, with anatomic site. Pharyngeal tumors had higher scores for nuclear grade compared with oral cavity and laryngeal tumors.

Increasing tumor stage was most strongly associated with overall tumor grade $(P=.003)$ and tumor keratinization $(P=.016)$. Tumor stage also showed suggestive positive associations with nuclear grade $(P$ $=.078)$ and mitotic index $(P=.052)$. Tumor stage was not associated with any of the tumor-host interface parameters examined. Of the eight chromosomal regions examined, only a negative association between advanced tumor stage (stage 3-4 versus stage 1-2) and loss of heterozygosity at 21q21-q22.2 was observed $(P=.018)$. However, this association did not show a consistent trend across the full range of tumor stages. Based on these findings, appropriate statistical adjustments were made for anatomic site and tumor 
stage in the analyses of allelic loss and tumor pathology/host interface parameters described below.

\section{Relationship between Allelic loss and Tumor Pathology/Host Interface Parameters}

Figure 2A graphically depicts the associations between allelic loss at the eight chromosomal regions investigated and the three different levels (low, me- dium, high) of the four tumor pathology parameters scored. For each chromosomal region-tumor parameter analytic pair, a series of three points is plotted in a left to right fashion (representing the progression from the low to high levels of the parameter in question) at the corresponding percentage of loss of heterozygosity. The strongest trend of association between increasing undifferentiated
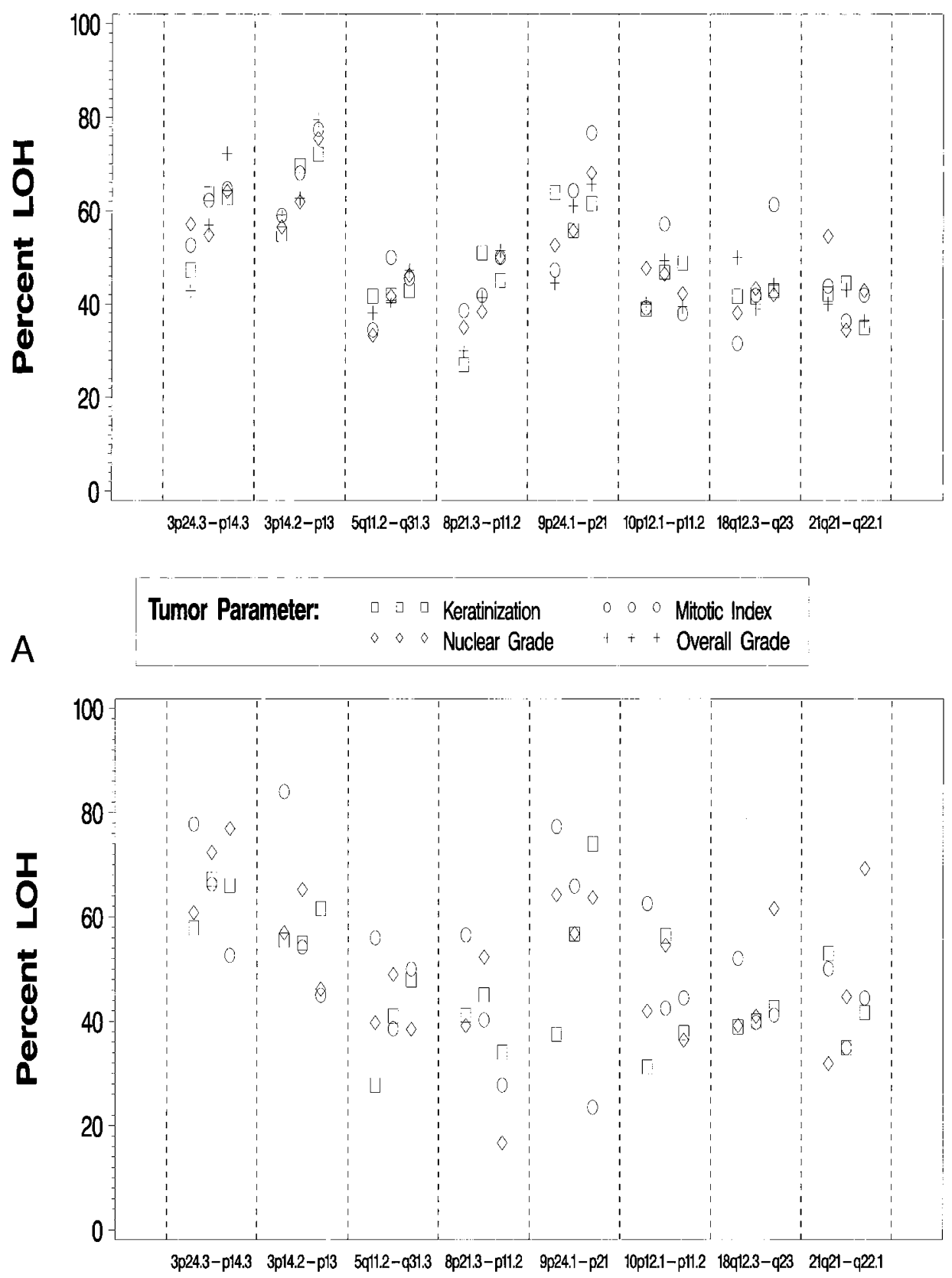

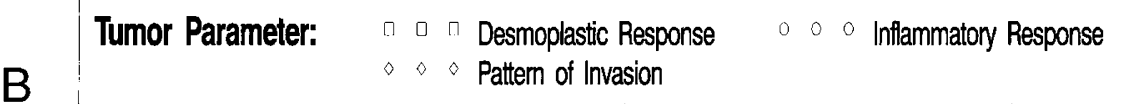

FIGURE 2. A, plot of percentage of loss of heterozygosity at eight separate chromosomal regions by increasing level (low, score $=1$; medium, score $=2$; high, score $=3$ or 4 ) of tumor pathology parameter in 139 primary head and neck cancer squamous cell tumors. B, plot of percentage of loss of heterozygosity at eight separate chromosomal regions by increasing level (low, score $=1$; medium, score $=2$; high, score $=3$ or 4 ) of tumorhost interface parameter in 139 primary head and neck cancer squamous cell tumors. 
overall tumor grade and increasing allelic loss was observed at 3p24.3-p14.3, 3p14.2-p13, 5q11.2-q31.3, 8p21.3-p11.2, and 9p24.2-p21. The two-sided $P$ values for an associated trend of increasing tumor grade with loss of heterozygosity at these five chromosomal regions were .032, .014, .335, .101 and .180 , respectively. For all of the five regions listed above, loss of heterozygosity appeared to increase in a linear fashion from the low to high levels of overall tumor grade. No trend of increasing allelic loss was observed between overall tumor grade and the other three chromosomal regions. For keratinization, the patterns of allelic loss at the eight regions and different amounts of keratinization were not as striking as those observed for overall tumor grade, but the chromosomal regions at which changes were observed were the same as that for overall tumor grade. The strongest trend was between allelic loss at 3p24.3-p14.3 and decreasing keratinization $(P=.042)$. Associated changes between nuclear grade and allelic loss were less prominent than both overall tumor grade and keratinization. For nuclear grade, the strongest trend was with allelic loss at 3p24.3-p14.3 $(P=.043)$. The most striking trends of increasing allelic loss with a higher mitotic index were for 3p24.3-p14.3 ( $P=.026), 9 p 24.2-\mathrm{p} 21(P=.004)$, and 18q12.3-q23 $(P=.009)$.

Figure $2 \mathrm{~B}$ is similar to Figure 2A, but for the three host-interface parameters scored. In general, most chromosomal regions had lower allelic loss with an increasing inflammatory response. The chromosomal regions with the strongest trend of association were 3p24.3-p14.3, 3p14.2-p13, 8p21.3-p11.2, and 9p24.2-p21 with trend test $P$ values of .089, $.008, .041$ and .001, respectively. For desmoplastic response, the region with the clearest trend (increasing) with increasing allelic loss was 9p24.2-p21 $(P=.009)$. A more modest trend was also observed between desmoplastic response and loss of heterozygosity at 5q11.2-q31.3 $(P=.082)$. An increase in the pattern of tumor invasion parameter was most strongly associated with an increasing allelic loss percentage at 21q21-q22.2 $(P=.015)$.

An overall inspection of Figure 2A-B reveals that 18q12.3-q23 loss and mitotic index and 21q21-q22.2 loss and tumor pattern of invasion were the most specific allelic loss-tumor parameter pairs. Of the eight chromosomal regions, 5q11.2-q31.3 was the least specific, with an increased loss of heterozygosity observed for all seven tumor/host interface parameters. Conversely, increasing loss at 21q21q22.2 only showed an association with changes in the tumor pattern of invasion parameter. In terms of strength of association, loss of heterozygosity at 9p24.2-p21 had the strongest associations with the pathologic parameters scored, for instance, mitotic index $(P=.004)$, inflammatory response $(P=.001)$, and desmoplastic response $(P=.009)$.

Based on our earlier analyses, anatomic site of the tumor could be a potential confounder in the relationship between allelic loss and the seven tumor pathologic parameters investigated; therefore we performed multivariate modeling to test significant associations independent of anatomic site. The regression $\beta$ coefficients and associated $P$ values shown in Table 4 are for combinations of tumor parameter-allelic loss regions for which anatomic site could be a potential confounder based on its strong relationship with both variables. For the two statistically significant chromosome $3 p$ associations with overall tumor grade, the adjustment for anatomic site only slightly decreased the absolute value of the regression $\beta$ coefficient, and in both instances this decrease was less than $10 \%$. The decrease in the absolute value for the regression $\beta$ coefficient for the nuclear grade/3p24.3-p14.3 association was also $<10 \%$. An adjustment for anatomic site had the largest effect on the other two statistically significant tumor parameter associations with allelic loss at chromosome 3p24.3-p14.3, keratinization and mitotic index. In both instances, the absolute value for the regression beta coefficient decreased $>10 \%$. The association between mitotic index and allelic loss at chromosome 10p12.1-p11.2 was the only other situation where confounding by anatomic site might occur, but adjustment for anatomic site slightly increased the absolute value of the regression beta coefficient, indicating that no negative confounding was present.

We performed multivariate modeling with generalized linear models for the four pathological parameters that were statistically significantly associ-

TABLE 4. The Effect of Adjustment for Anatomic Site on the Association between Selected Pathologic Parameters and Tumor Allelic Loss

\begin{tabular}{llcccc}
\hline \multirow{2}{*}{ Pathologic parameter } & Site of LOH & \multicolumn{2}{c}{ Crude } & & \multicolumn{2}{c}{ Adjusted for Site } \\
\cline { 3 - 5 } & & $\beta^{a}$ & $P$ Value & & $\beta$ \\
\hline Overall grade & 3p14.2-p13 & -0.72 & 0.016 & -0.66 & 0.035 \\
Overall grade & 3p24.3-p14.3 & -0.64 & 0.035 & -0.61 & 0.057 \\
Keratinization & 3p24.3-p14.3 & -0.49 & 0.045 & -0.42 & 0.097 \\
Nuclear grade & 3p24.3-p14.3 & -0.53 & 0.045 & -0.48 & 0.079 \\
Mitotic index & 3p24.3-p14.3 & -0.56 & 0.028 & -0.44 & 0.096 \\
Mitotic index & 10p12.1-p11.2 & -0.73 & 0.005 & -0.76 & 0.009 \\
\hline
\end{tabular}

${ }^{a}$ Beta coefficient. 


\begin{tabular}{|c|c|c|c|}
\hline Pathologic Parameter & Model Parameters $^{a}$ & $\begin{array}{l}\text { Chi-Squared } \\
\text { Statistic }\end{array}$ & $P$ Value \\
\hline \multirow[t]{2}{*}{ Overall grade } & 1. 3p14.2-p13 & 4.95 & 0.026 \\
\hline & 2. 3p14.2-p13 + 3p24.3-p14.3 & 1.25 & 0.262 \\
\hline \multirow[t]{3}{*}{ Mitotic index } & 1. $9 \mathrm{p} 24.2-\mathrm{p} 21$ & 8.23 & 0.004 \\
\hline & 2. $9 \mathrm{p} 24.2-\mathrm{p} 21+18 \mathrm{q} 12.3-\mathrm{q} 23$ & 2.40 & 0.121 \\
\hline & 3. $9 \mathrm{p} 24.2-\mathrm{p} 21+3 \mathrm{p} 24.3-\mathrm{p} 14.3$ & 2.52 & 0.113 \\
\hline \multirow[t]{2}{*}{ Inflammatory response } & 1. 3p14.2-p13 & 10.04 & 0.002 \\
\hline & 2. 3p14.2-p13 + 9p24.2-p21 & 7.69 & 0.006 \\
\hline \multirow[t]{2}{*}{ Desmoplastic response } & 1. $9 \mathrm{p} 24.2-\mathrm{p} 21$ & 8.41 & 0.004 \\
\hline & 2. $9 \mathrm{p} 24.2-\mathrm{p} 21+5 \mathrm{q} 11.2-\mathrm{q} 31.3$ & 1.46 & 0.227 \\
\hline
\end{tabular}

${ }^{a}$ All models include intercept.

ated with allelic loss at two or more chromosomal regions (Table 5). Allelic loss variables were introduced into the model in the order of their magnitude of statistical significance on a univariate level. For overall tumor grade, a variable for allelic loss at 3p14.2-p13 was statistically significant $(P=.026)$, but no further allelic loss variables significantly decreased the model deviance. In the next set of models with mitotic index as the dependent variable, introduction of the 9p24.2-p21 allelic loss variable resulted in a statistically significant reduction of the model deviance $(P=.004)$. Adding variables for allelic loss at either 18q12.3-q23 $(P=.121)$ or 3p24.3-p14.3 $(P=.113)$ did not further significantly reduce the model deviance. A similar model fitting process was followed for inflammatory response as the dependent variable. Here, both 3p14.2-p13 ( $P=$ $.002)$ and 9p24.2-p21 $(P=.006)$ reduced the model deviance to a statistically significant degree. For the desmoplastic response parameter, only allelic loss at 9p24.2-p21 was statistically significant $(P=.004)$ in the multivariate model.

Fractional allelic loss was used as a summary measure of allelic loss across all eight regions. Figure 3 shows mean fractional allelic loss levels across the low, medium, and high levels of the seven pathologic parameters studied. Fractional allelic loss varied with regard to overall tumor grade, keratinization, mitotic index, and inflammatory response, but only the variation of mean fractional

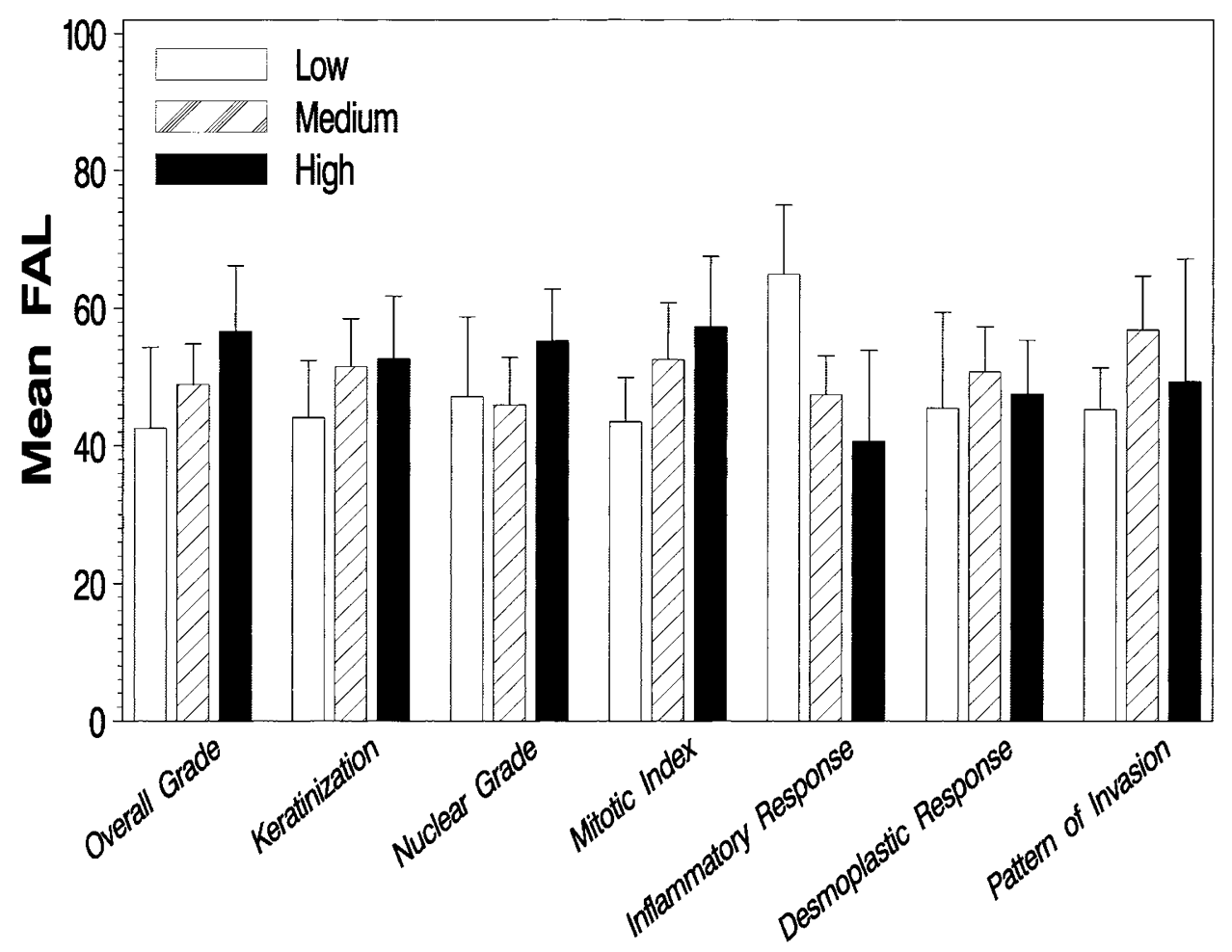

Pathological Parameter

FIGURE 3. Mean fractional allelic loss over eight separate chromosomal regions in 139 primary head and neck cancer squamous cell tumors at three levels (low, score $=1$; medium, score $=2$; high, score $=3$ or 4 ) of tumor pathology and host interface parameters. 
allelic loss with mitotic index $(P=.032)$ and inflammatory response $(P=.006)$ were significant at the .05 alpha level.

\section{DISCUSSION}

Allelic loss is a common occurrence in head and neck squamous cell carcinoma tumors. One hypothesis is that allelic loss is part of the carcinogenesis process, with the genetic alterations that are characterized by allelic loss inactivating tumor suppressor genes that lie within the region of loss. For instance, the chromosome region 9p21-p24, which corresponds to the p16 (cyclin-dependent kinase inhibitor 2A) tumor suppressor gene region, is one of the most frequently lost regions in head and neck squamous cell carcinoma (21). Other supporting evidence for allelic loss as an important marker in head and neck squamous cell carcinoma carcinogenesis is the association of allelic loss in premalignant oral lesions with malignant potential (11-13), survival $(5,7,10,22)$, and tumor recurrence $(6,23$, 24 ) in head and neck squamous cell carcinoma cases. The present study examined allelic loss in head and neck squamous cell tumors in relation to the pathologic characteristics of these tumors. Because carcinogenesis is a multistep process that is measurable on the cellular level through different pathologic indices, we hypothesized that loss of specific tumor suppressor genes may trigger specific pathologic events. Therefore, tumor allelic loss at genetic markers mapped to tumor suppressor genes that play a role in tumor pathology or host response should be associated with the corresponding tumor parameters.

A good example of how allelic loss might help explain pathologic events in head and neck squamous cell carcinoma is the correlation that we found between allelic loss at chromosome 21q21q22 and the host interface parameter, tumor pattern of invasion. This association was highly specific, and upon investigation of the associations between the individual markers that spanned the 21q21-q22 region and tumor pattern of invasion, a strong candidate gene for this association emerged. Of the three 21q21-q22 markers, the IFNAR marker, which mapped to chromosome 21q22, had the strongest association with tumor pattern of invasion $(P=.010)$. This marker maps only $1.1 \mathrm{mB}$ from the T-cell lymphoma invasion and metastasis 1 (TIAM1) gene. This gene is thought to be important in the development or metastasis of malignancies that are associated with abnormalities on chromosome 21 (25). In fibroblasts, TIAM1 induces a phenotype that includes membrane ruffling and invasion (26). Our findings strongly suggest that TIAM1 may play a similar role in head and neck carcinogenesis.
Published results of cDNA microarray analyses of genes differentially expressed in head and neck squamous call carcinoma are also useful resources to search for possible candidate genes of pathologic changes in this cancer. Of a list of 23 genes expressed at a higher level in normal oral epithelium compared with oral malignant tissue (27), two genes, Cystatin B (CSTB) and Hypothetical Protein FLJ10375, map to $21 \mathrm{q} 22$ and 3p21, two regions in which we found significant pathologic correlations with loss of heterozygosity. The function of the Hypothetical Protein FLJ10375 gene is unknown, but cystatin proteins have been reported previously to be associated with a metastatic tumor cell phenotype and to be important in head and neck cancer (28). Therefore, in addition to TIAM1, CSTB is also a potential candidate gene for playing a role in tumor pattern of invasion in head and neck squamous cell carcinoma.

Several studies have tried to link tumor and host interface parameters with head and neck cancer prognosis $(15,16,18)$, but few studies have tried to correlate any head and neck squamous cell carcinoma tumor histologic parameters with allelic loss. Two separate studies have shown that lymph node metastasis in oral cancer patients was correlated with allelic loss at chromosomes 13q14.3 (29) and 2q35 (30), respectively. We could not evaluate lymph node metastasis in most of our cases, nor did we evaluate allelic loss at these two regions. Although few studies comparable to the present study exist, it is worth noting that allelic loss at the chromosome 9p24.2-p21 region, which we found strongly correlated with several tumor parameters, including mitotic index, inflammatory response, and desmoplastic response, also has been shown to be a strong predictor of survival in this same study population (31). This survival result substantiates the importance of chromosome 9p24.2-p21 loss in our study population, and the current study suggests that loss of this region may inhibit the host's ability to respond to a growing tumor cell population. On a pathologic level, this would explain our survival result as well as the strong correlation between chromosome 9p loss and tumor recurrence (32).

Patients for this study were recruited sequentially and were clinically and demographically representative of the larger population of head and neck cancer patients in the Detroit area (33). Pathology review was done blinded of genetic results and clinical outcomes. DNA analysis was done either on fresh tissue of high tumor purity $(>90 \%)$ or paraffin blocks with DNA amplification of the block area identified as tumor by the study pathologist. Contamination of tumor tissue with normal tissue could still have happened in some instances and have led to an underestimate of allelic loss. Like- 
wise, although pathologic evaluations were done in a careful fashion so as to best evaluate the overall character of the tumor in question, tumors of a higher degree of histologic heterogeneity may have been pathologically misrepresented. Because the great majority $(>90 \%)$ of the tumors in our study were of the conventional squamous cell histologic subtype, our results may not be representative of other less common histologies found in head and neck squamous cell carcinoma. Probably the greatest limitation of this study is its inability to temporally relate the observed allelic losses with the events that result in the pathologic parameters measured. Because the data from this study were cross-sectional, we had no way of showing a temporal relationship between allelic loss and the pathologic phenomena of interest in this study.

In summary, we found significant associations between selected tumor pathologic parameters of head and neck squamous cell carcinoma and allelic loss at specific chromosomal regions. In some instances, allelic loss mapped closely to a specific tumor suppressor gene that could play a role in manifesting the pathologic parameter in question (i.e., pattern of tumor invasion and the TIAM1 and CSTB genes on chromosome 21q22). Alternatively, allelic loss at chromosome 9p24.2-p21, associated with the early stages of head and neck squamous cell carcinogenesis $(12,13)$, was strongly associated with several host interface parameters suggesting a loss of function in a gene or genes that mediate pathways of immune-response to malignant growth. In three of the four instances in which two or more regions of allelic loss were associated with a tumor parameter, multivariate analyses showed that the loss at these regions was redundant (see Table 5). This suggests that loss at only one of the regions in question may play a causal role in the pathologic trend observed, but this can only be teased apart definitively with larger data sets of diverse tumor populations. Nevertheless, our study represents a first step in trying to understand the relationship between changes at the cellular DNA level and the subsequent pathologic manifestations. Future studies of large and diverse tumor populations can build upon these findings by using denser genetic marker maps to link specific genes with the pathologic phenomena that they orchestrate in head and neck squamous cell carcinoma.

\section{REFERENCES}

1. Gasparotto D, Vukosavljevic T, Piccinin S, Barzan L, Sulfaro S, Armellin M, et al. Loss of heterozygosity at 10q in tumors of the upper respiratory tract is associated with poor prognosis. Int J Cancer 1999;84:432-6.

2. Ishwad CS, Shuster M, Bockmuhl U, Thakker N, Shah P, Toomes C, et al. Frequent allelic loss and homozygous de- letion in chromosome band 8p23 in oral cancer. Int J Cancer 1999;80:25-31.

3. El-Naggar AK, Hurr K, Huff V, Luna MA, Goepfert H, Batsakis JG. Allelic loss and replication errors at microsatellite loci on chromosome 11p in head and neck squamous carcinoma: association with aggressive biological features. Clin Cancer Res 1996;2:903-7.

4. Mao EJ, Schwartz SM, Daling JR, Beckmann AM. Loss of heterozygosity at 5q21-22 (adenomatous polyposis coli gene region) in oral squamous cell carcinoma is common and correlated with advanced disease. J Oral Pathol Med 1998; 27:297-302.

5. Pearlstein RP, Benninger MS, Carey TE, Zarbo RJ, Torres FX, Rybicki BA, et al. Loss of 18q predicts poor survival of patients with squamous cell carcinoma of the head and neck. Genes Chromosomes Cancer 1998;21:333-9.

6. Matsuura K, Shiga K, Yokoyama J, Tateda M, Nakano H, Saijo S, et al. Loss of heterozygosity of 3p21 and 9p21 in head and neck squamous cell carcinomas and its prognostic implication. Nippon Jibiinkoka Gakkai Kaiho 1999;102:613-21.

7. Lee DJ, Koch WM, Yoo G, Lango M, Reed A, Califano J, et al. Impact of chromosome 14q loss on survival in primary head and neck squamous cell carcinoma. Clin Cancer Res 1997;3: 501-5.

8. Bockmuhl U, Schluns K, Kuchler I, Petersen S, Petersen I. Genetic imbalances with impact on survival in head and neck cancer patients. Am J Pathol 2000;157:369-75.

9. Lydiatt WM, Davidson BJ, Schantz SP, Caruana S, Chaganti RS. 9p21 deletion correlates with recurrence in head and neck cancer. Head Neck 1998;20:113-8.

10. Partridge M, Emilion G, Langdon JD. LOH at 3p correlates with a poor survival in oral squamous cell carcinoma. Br J Cancer 1996;73:366-71.

11. Partridge M, Emilion G, Pateromichelakis S, A'Hern R, Phillips E, Langdon J. Allelic imbalance at chromosomal loci implicated in the pathogenesis of oral precancer, cumulative loss and its relationship with progression to cancer. Oral Oncol 1998;34:77-83.

12. Rosin MP, Cheng X, Poh C, Lam WL, Huang Y, Lovas J, et al. Use of allelic loss to predict malignant risk for low-grade oral epithelial dysplasia. Clin Cancer Res 2000;6:357-62.

13. Mao L, Lee JS, Fan YH, Ro JY, Batsakis JG, Lippman S, et al. Frequent microsatellite alterations at chromosomes 9p21 and 3p14 in oral premalignant lesions and their value in cancer risk assessment. Nat Med 1996;2:682-5.

14. Jiang WW, Fujii H, Shirai T, Mega H, Takagi M. Accumulative increase of loss of heterozygosity from leukoplakia to foci of early cancerization in leukoplakia of the oral cavity. Cancer 2001;92:2349-56.

15. Klijanienko J, El-Naggar AK, de Braud F, Rodriguez-Peralto JL, Rodriguez R, Itzhaki M, et al. Tumor vascularization, mitotic index, histopathologic grade, and DNA ploidy in the assessment of 114 head and neck squamous cell carcinomas. Cancer 1995;75:1649-56.

16. Yilmaz T, Hosal AS, Gedikoglu G, Kaya S. Prognostic significance of histopathological parameters in cancer of the larynx. Eur Arch Otorhinolaryngol 1999;256:139-44.

17. Janot F, Klijanienko J, Russo A, Mamet JP, de Braud F, El-Naggar AK, et al. Prognostic value of clinicopathological parameters in head and neck squamous cell carcinoma: a prospective analysis. Br J Cancer 1996;73:531-8.

18. Lehn CN, Rapoport A. The desmoplastic lymph node reaction as a prognostic factor of cancer of the tongue and floor of the mouth. Rev Paul Med 1994;112:591-6.

19. Crissman JD, Zarbo RJ. Squamous cell carcinoma of the upper aerodigestive tract: histologic parameters with prognostic value. In: Chretien PB, editor. Head and neck cancer. Philadelphia: B.C. Decker, Inc.; 1990. p. 65-8.

20. Agresti A. Categorical data analysis. New York: Wiley; 1990. 
21. Gollin SM. Chromosomal alterations in squamous cell carcinomas of the head and neck: window to the biology of disease. Head Neck 2001;23:238-53.

22. Field JK, Kiaris H, Risk JM, Tsiriyotis C, Adamson R, Zoumpourlis V, et al. Allelotype of squamous cell carcinoma of the head and neck: fractional allele loss correlates with survival. Br J Cancer 1995;72:1180-8.

23. Lazar AD, Winter MR, Nogueira CP, Larson PS, Finnemore EM, Dolan RW, et al. Loss of heterozygosity at 11q23 in squamous cell carcinoma of the head and neck is associated with recurrent disease. Clin Cancer Res 1998;4:2787-93.

24. Lydiatt WM, Davidson BJ, Schantz SP, Caruana S, Chaganti RS. 9p21 deletion correlates with recurrence in head and neck cancer. Head Neck 1998;20:113-8.

25. Chen H, Antonarakis SE. Localization of a human homolog of the mouse Tiam-1 gene to chromosome 21q22.1. Genomics 1995;30:123-7.

26. Michiels F, Habets GG, Stam JC, van der Kammen RA, Collard JG. A role for Rac in Tiam1-induced membrane ruffling and invasion. Nature 1995;375:338-40.

27. Leethanakul C, Knezevic V, Patel V, Amornphimoltham P, Gillespie J, Shillitoe EJ, et al. Gene discovery in oral squamous cell carcinoma through the Head and Neck Cancer
Genome Anatomy Project: confirmation by microarray analysis. Oral Oncol 2003;39:248-58.

28. Kos J, Lah TT. Cysteine proteinases and their endogenous inhibitors: target proteins for prognosis, diagnosis and therapy in cancer. Oncol Rep 1998;5:1349-61.

29. Ogawara K, Miyakawa A, Shiba M, Uzawa K, Watanabe T, Wang XL, et al. Allelic loss of chromosome 13q14.3 in human oral cancer: correlation with lymph node metastasis. Int J Cancer 1998;79:312-7.

30. Yamamoto N, Mizoe J, Numasawa H, Yokoe H, Uzawa K, Shibahara T, et al. Allelic loss of chromosome 2 in human oral squamous cell carcinoma: correlation with lymph node metastasis. Oral Oncol 2003;39:64-8.

31. Coon SW, Savera AT, Zarbo RJ, et al. Prognostic implications of loss of heterozygosity at 8p21 and 9p21 in head and neck squamous cell carcinoma. Int J Cancer (in press).

32. Rosin MP, Lam WL, Poh C, Le ND, Li RJ, Zeng T, et al. 3p14 and 9p21 loss is a simple tool for predicting second oral malignancy at previously treated oral cancer sites. Cancer Res 2002;62:6447-50.

33. Ries LAG, Eisner MP, Kosary CL, Hankey BF, Miller BA, Clegg L, et al. SEER cancer statistics review, 1973-1998. Bethesda, MD: National Cancer Institute; 2001. 